
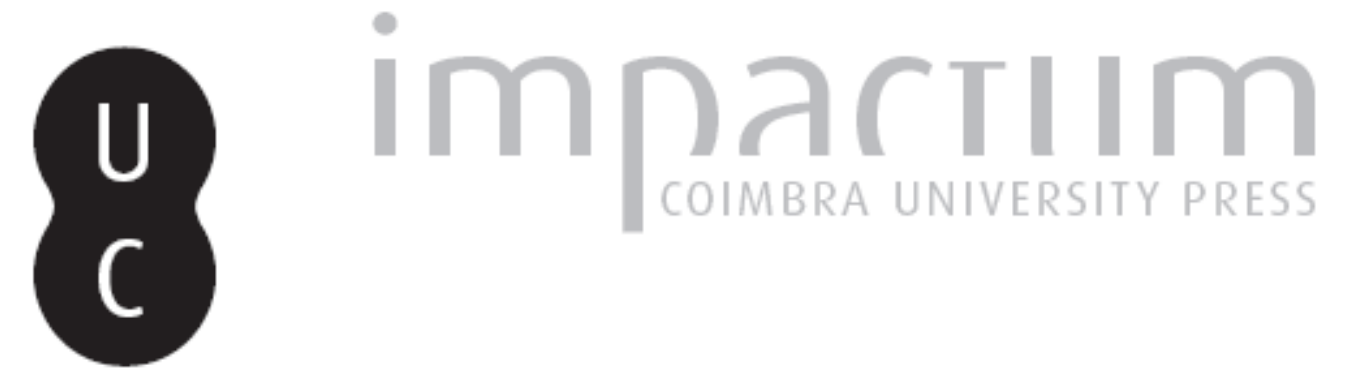

\title{
Um novo olhar sobre os riscos? 0 exemplo das cheias rápidas (flash floods) em domínio mediterrâneo
}

\author{
Autor(es): $\quad$ Rebelo, Fernando \\ Publicado por: Associação Portuguesa de Riscos, Prevenção e Segurança \\ URL \\ persistente: \\ URI:http://hdl.handle.net/10316.2/36193 \\ DOI: \\ DOI:http://dx.doi.org/10.14195/1647-7723_15_1 \\ Accessed : $\quad$ 26-Apr-2023 10:42:10
}

A navegação consulta e descarregamento dos títulos inseridos nas Bibliotecas Digitais UC Digitalis, UC Pombalina e UC Impactum, pressupõem a aceitação plena e sem reservas dos Termos e Condições de Uso destas Bibliotecas Digitais, disponíveis em https://digitalis.uc.pt/pt-pt/termos.

Conforme exposto nos referidos Termos e Condições de Uso, o descarregamento de títulos de acesso restrito requer uma licença válida de autorização devendo o utilizador aceder ao(s) documento(s) a partir de um endereço de IP da instituição detentora da supramencionada licença.

Ao utilizador é apenas permitido o descarregamento para uso pessoal, pelo que o emprego do(s) título(s) descarregado(s) para outro fim, designadamente comercial, carece de autorização do respetivo autor ou editor da obra.

Na medida em que todas as obras da UC Digitalis se encontram protegidas pelo Código do Direito de Autor e Direitos Conexos e demais legislação aplicável, toda a cópia, parcial ou total, deste documento, nos casos em que é legalmente admitida, deverá conter ou fazer-se acompanhar por este aviso.

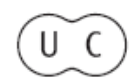




\section{territorium}

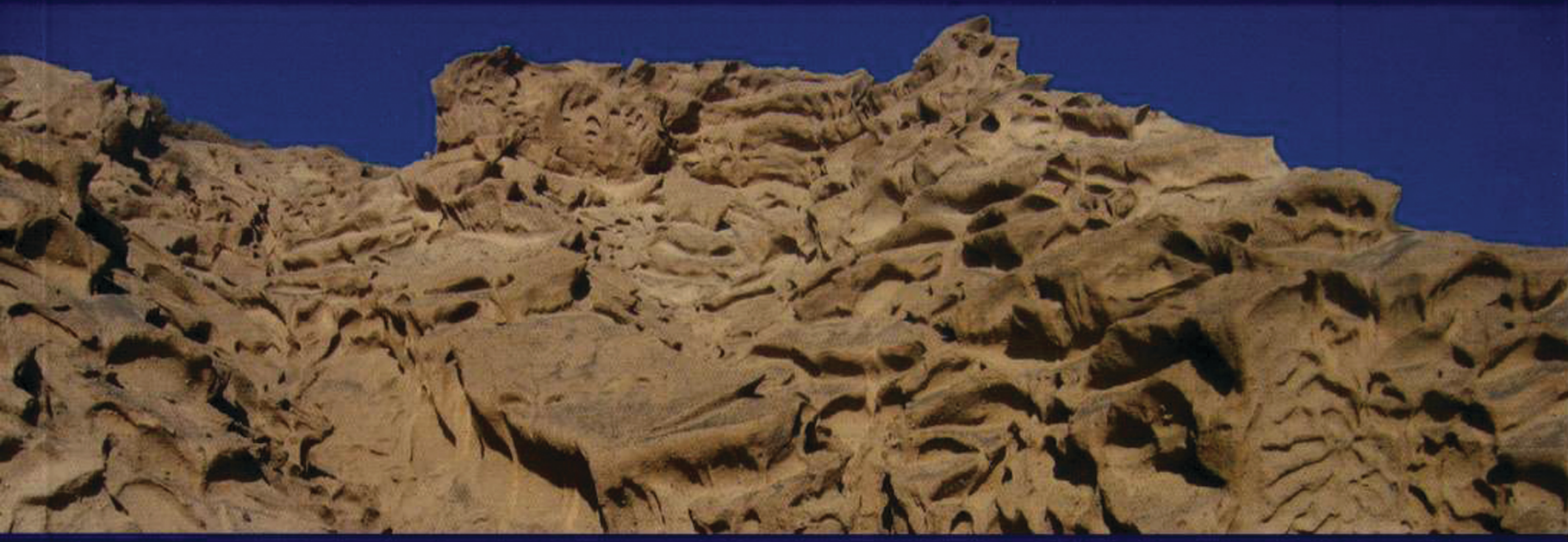

15

Revista da Associação Portuguesa de Riscos, Prevenção e Segurança 2008 


\title{
UM NOVO OLHAR SOBRE OS RISCOS? O EXEMPLO DAS CHEIAS RÁPIDAS (FLASH FLOODS) EM DOMÍNIO MEDITERRÂNEO.
}

Fernando Rebelo

fsrebelo@ci.uc.pt

Professor Catedrático. Instituto de Estudos Geográficos Faculdade de Letras da Universidade de Coimbra

\begin{abstract}
RESUMO
A análise de um risco clássico no domínio mediterrâneo, o risco de cheias rápidas, bem conhecido na região de Lisboa, conduz a uma reflexão sobre a importância das acções humanas como factor agravante dos processos potencialmente perigosos e ao mesmo tempo como responsáveis pelas vulnerabilidades. Um novo olhar sobre os riscos vai por isso no sentido do respeito pela legislação existente relacionada com ordenamento do território, bem como na preparação dos agentes de protecção civil para a percepção do perigo e para a gestão da crise.
\end{abstract}

Palavras-chave: Cheias rápidas, Lisboa, mudanças climáticas, risco, perigo, crise.

\begin{abstract}
The analysis of one of the most classic risks in the Mediterranean climatic area, flash floods, well known in Lisbon region, is the reason to the present reflection about man made acceleration of hazards and, at the same time, about man responsibility in vulnerabilities. A new look on risks is going to the respect of the planning legislation as well as to the preparation of civil protection agents in the perception of danger and the management of the crisis.
\end{abstract}

Key words: Flash floods, Lisbon, climate change, hazard and risk, danger, crisis.

\section{RÉSUMÉ}

L'analyse d'un risque classique dans le domaine méditérranéen, le risque de crues rapides (bien connu dans la région de Lisbonne) conduit à une réflexion sur l'importance des actions humaines en tant que facteurs $d^{\prime}$ agravement des aléas et en même temps en tant que responsables des vulnerabilités. Un nouveau regard sur les risques est directionné pour le respect de la législation de l'aménagement du térritoire, ainsi que pour la préparation des agents de la sécurité civile sur la perception du danger et la maîtrise de la crise.

Mots clés: Crues rapides, Lisbonne, changements climatiques, aléa et risque, danger, crise. 


\section{Introdução}

Um novo olhar sobre os riscos é o que se propõe a partir da definição do climatólogo francês André Dauphiné, pela qual o risco é entendido como uma relação entre "aléa" ou "hazard" (processo potencialmente perigoso) e vulnerabilidade, relação esta analisada caso a caso (A. DAUPHINÉ, 2001). São muitos os riscos, mas em todos há uma componente estranha ao querer do Homem e uma outra componente que é a exposição do próprio Homem à primeira. No entanto, mesmo na que lhe é estranha e que pode ter uma origem natural, o Homem chega a ser responsabilizado por acções conscientes ou inconscientes que the venham a conferir maior intensidade. A vulnerabilidade, por seu lado, é, totalmente, criada por si.

Desde o seu início, a Geografia estudou os processos através da observação das suas consequências mais do que através da observação do seu desenvolvimento, por vezes, demasiado lento, por vezes, rápido em demasia. Os processos deduziramse, quase sempre, com apoio em dados históricos. No passado, muito antes da existência da Geografia moderna, já havia consciência das acções humanas que aceleravam processos naturais. Um caso bem conhecido em Portugal relaciona-se com os desbastes de árvores ou com as queimadas nas vertentes do rio Mondego e de seus afluentes, a montante das áreas então frequentemente inundadas na planície aluvial. A título de exemplo, pode referir-se "a carta régia de 22 de Setembro de 1464", pela qual, "Dom Afonso V tenta atacar o mal na origem", proibindo "as queimadas desde Coimbra a Seia" (A. F. MARTINS, 1940, p. 178-179). Hoje, sem dúvida, há bem mais consciência dessas acções humanas.

Por outro lado, a vulnerabilidade para cada tipo de risco também vem sendo conhecida através de experiências mais ou menos traumatizantes, quando os riscos se manifestam.

Em Portugal, no dia 18 de Fevereiro de 2008, viveramse, momentos difíceis com as cheias rápidas (flash floods) que voltaram a ocorrer na região de Lisboa. As chuvas intensas foram a base do problema, mas os efeitos do escoamento das águas foram agravados por acções humanas desajustadas ou por negligências. No entanto, a vulnerabilidade, no conjunto da região, pareceu inferior à que se verificava noutros tempos.

O ordenamento do território, nas suas tão diversificadas facetas, actuando a montante das áreas de risco de inundação ou sobre elas próprias, tem vindo a diminuir alguns factores de agravamento dos processos, tal como muitas vulnerabilidades para vários riscos relacionados com o risco principal, que é o da ocorrência de cheias rápidas. $O$ ensinamento da catástrofe da região de Lisboa em 1967 revelouse fundamental na legislação portuguesa e, apesar de se manterem algumas questões pontuais, que terão de ser estudadas e resolvidas, há motivos para encarar o futuro com optimismo, desde que não se permita o regresso de velhas vulnerabilidades ou o aparecimento de novas.

\section{Um risco clássico no domínio mediterrâneo: o risco de cheias rápidas}

2.1. Os mais antigos documentos em que é utilizada a palavra risco datam do século XIII - foram escritos em Génova e estão ligados com a vida do mar (C. VILLAIN-GANDOSSI, 1990). De início, associava-se muito o risco com fortuna ou sorte. No entanto, depressa o risco começou a relacionar-se e até a confundir-se com o perigo, o que permaneceu até aos nossos dias. A noção de risco associada à de seguro também aparece muito cedo, ao passo que a noção de risco relacionada com a de crise é mais recente. Hoje, risco é considerado como probabilidade de ocorrência de acontecimento danoso, enquanto perigo corresponde à proximidade da manifestação do risco e crise é a manifestação do risco fora do controlo do Homem (L. Faugères, 1990 a, 1990 b, 1991 ; F. Rebelo, 2001,2003 e 2005 a).

Depois de muitas tentativas, em especial, da parte de engenheiros e de economistas, para reduzir risco a uma fórmula matemática, mais ou menos complexa, talvez porque a geografia estuda espaços diferenciados, $\mathrm{A}$. DAUPHINÉ $(2001$, p. 24) veio propor que risco fosse considerado, muito simplesmente, como função de aléa e de vulnerabilidade, numa relação que depende do problema analisado. Por outras palavras, o risco deverá ser considerado função de um processo potencialmente perigoso (aléa, para os francófonos, ou hazard, para os anglófonos) e do modo como as populações se expõem a esse processo (vulnerabilidade).

Deste modo, a intervenção do Homem terá de ser analisada nas duas componentes da função, dado que pode desencadear factores de agravamento do risco que têm de ser entendidos tanto a nível do hazard, como a nível da vulnerabilidade. A gestão do risco exige, portanto, em primeiro lugar, o conhecimento do processo potencialmente perigoso 
e de todo o trabalho humano que o possa intensificar. Depois, exige o conhecimento do modo de distribuição da população pela área que possa ser atingida pelo desencadear do processo, ou seja, o conhecimento do grau de exposição ao processo.

2.2. Assim entendida a noção de risco, parece interessante aplicá-la a um risco clássico no domínio mediterrâneo, que mais uma vez se manifestou na região de Lisboa, no passado dia 18 de Fevereiro de 2008.

Cheias rápidas podem ocorrer um pouco por todo o mundo. Não parece que devam ser consideradas zonais. Ocorrem na zona intertropical, como ocorrem na orla dos desertos ou em qualquer dos domínios da zona temperada. No entanto, a frequência com que acontecem em áreas de clima temperado mediterrâneo com grande densidade populacional justifica uma análise particular à luz da teoria do risco.

Na literatura geográfica ficaram registadas chuvas muito intensas, mas "os recordes parecem pertencer às regiões mediterrâneas: Molitg-les-Bains (Pirinéus Orientais) recebeu $313 \mathrm{~mm}$ de água em 1 hora e meia, a 20 de Março de 1868; Marselha $210 \mathrm{~mm}$ em $3 \mathrm{~h}$ e $50 \mathrm{~m}$ (dos quais $150 \mathrm{em} 2$ horas), no 1 ㅇ de Outubro de 1892. Quando da catástrofe do Orba (Itália), em Agosto de 1933, um pluviómetro recebeu $554 \mathrm{~mm}$ em 8 horas" (Ch. P. PÉGUY, 1970, p.200). No entanto, quando os estudos hidrológicos se começam a fazer numa perspectiva de riscos, os exemplos que se salientam são bem mais recentes - em França estudaram-se, então, casos como os de Nîmes (1988) e de Vaison-La-Romaine (1992). Na génese das cheias rápidas de Nîmes, "a precipitação ultrapassou por todo o lado 300 mm", um pluviómetro dos arredores atingiv $420 \mathrm{~mm}$; "a intensidade média foi relativamente regular, da ordem de $50 \mathrm{~mm}$ por hora, com máximos pontuais que certamente se aproximaram dos 100 $\mathrm{mm}$; as intensidades máximas mantiveram-se durante perto de seis horas" (A. VilleVIeIlle, 1997, p.55). Morreram apenas 10 pessoas, mas perderam-se 1655 viaturas. Ainda mais recentemente, "o acontecimento pluvioso de 8 e 9 de Setembro de 2002 está entre os mais violentos registados (...) no Languedoc-Roussillon e na Provence-Alpes-Côte d'Azur" com valores que, pontualmente, atingiram "até $687 \mathrm{~mm}$ em 24 h"; é certo que as cheias rápidas resultantes verificaram-se num domingo, talvez por isso houve só "23 mortos, dos quais 22 no departamento do Gard", mas os prejuízos foram enormes por quase todo o Sul de França (M.E.D.D., 2004). A análise desta catástrofe levou à elaboração e posterior publicação de um Relatório enriquecido com vários estudos científicos - Crues du Gard 2002: retour d'expérience - que se revela de grande importância para o conhecimento deste tipo de riscos.

2.3. No caso das cheias catastróficas da região de Lisboa, ocorridas na madrugada do dia 26 de Novembro de 1967, I. AmArAL (1968) analisou o processo com grande pormenor (F. Rebelo, 1997, $2001,2003,2005$ a). A componente natural resultara de chuva intensa (depressão e frente fria associada), quando havia já grande abundância de água nos solos. A área com maior precipitação foi a do Estoril. $\mathrm{Na}$ estação meteorológica do Monte Estoril registaram-se $60 \mathrm{~mm}$ de precipitação entre as 20 e as $21 \mathrm{~h}$ de 25 de Novembro. Em 24 horas, das $10 \mathrm{~h}$ de 25 às $10 \mathrm{~h}$ de 26 , o total foi de $158,7 \mathrm{~mm}$. Na estação de São Julião do Tojal, registaram-se $111 \mathrm{~mm}$ entre as 19 e as 24 h do dia 25 .

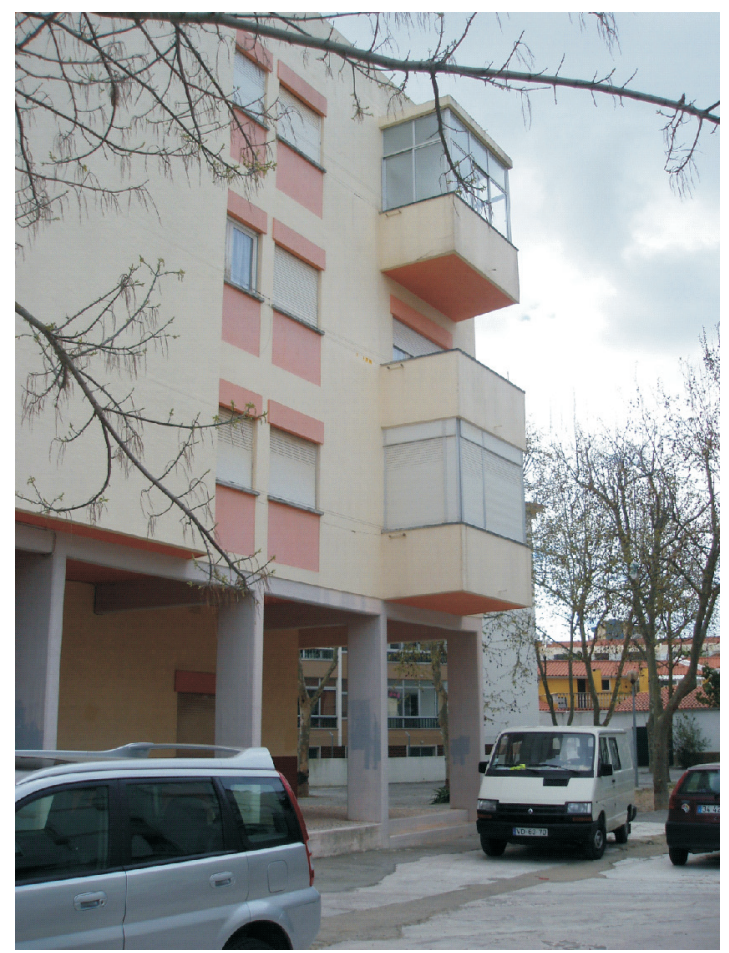

Fot. 1 - Alapraia, São João do Estoril. Às $23 \mathrm{~h} 30 \mathrm{~m}$ de 25 de Novembro de 1967 este prédio encontrava-se rodeado de água até $1,5 \mathrm{~m}$ de altura.

Numa das áreas mais atingidas (Rio Trancão), a bacia de drenagem apresentava forte circularidade, originando resposta mais rápida às chuvas, e fracos declives na proximidade do Tejo. Noutros casos, não se verificando a circularidade, verificaram-se outros factos não menos importantes, mas de origem humana. Desde logo, ficaram clarificados vários factores de agravamento para o processo que então se manifestava: por um lado, a impermeabilização exagerada de áreas urbanas e a falta de preparação dos esgotos, por outro lado, as vertentes desnudadas 
de vegetação e os solos abandonados pela lavoura (I. AmARAL, 1968).

Perante qualquer objecto de estudo, há perguntas clássicas que o geógrafo coloca a si próprio. Onde? Quando? Como? Porquê ali? A resposta à última exige, antes de mais, a consideração de factos

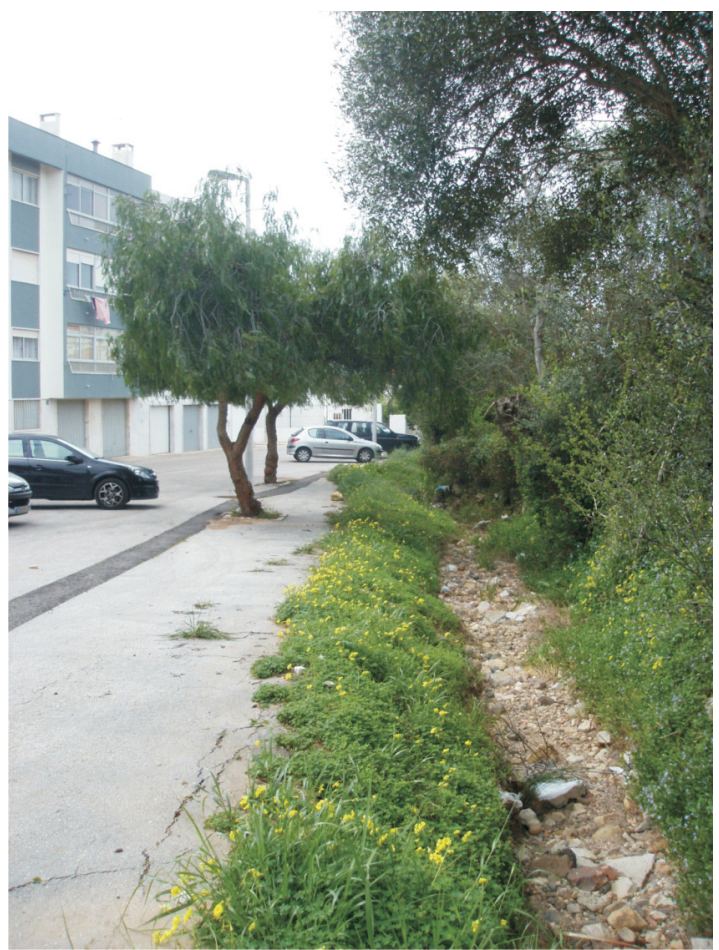

Fot. 2 - Alapraia, São João do Estoril. Vala que se transformou em "rio" caudaloso durante a noite de 25 para 26 de Novembro de 1967. Os prédios são posteriores e ocupam um espaço, então, parcialmente cultivado. Aí existiam várias barracas de madeira, uma das quais habitada, que foram inundadas enquanto um muro transversal serviu de barragem. Com o colapso do muro as águas destruiram e levaram os seus restos.

relacionados com a acção humana que aceleram ou intensificam os processos naturais. E aqueles salientavam-se aos olhos do geógrafo. Mas as consequências da manifestação de um risco qualquer têm, igualmente, a ver com o modo como o Homem se expõe aos processos em causa - a vulnerabilidade. E nas cheias rápidas de 1967 elas eram muitas. Não faltavam construções em leitos de cheia e construções sobre talvegues; em situações semelhantes estavam também muros e estradas antigas, pontes subdimensionadas e numerosas barracas de madeira (muitas das quais habitadas). Através das fotografias que publicou, I. Amaral (1968) mostrou bem como ficaram destruídas, total ou parcialmente.

A manifestação do risco de cheia rápida na noite de 25 para 26 de Novembro de 1967 revestiu a forma de crise no seu mais elevado grau, a catástrofe. Nunca se saberá ao certo quantas pessoas sucumbiram em toda a região de Lisboa. Sendo certo que os números apresentados pecaram por defeito $(427$, segundo o Diário de Notícias de 29 de Novembro de 1967), mas que alguns números, indicados dezenas de anos depois, podem pecar por excesso (cerca de 700, segundo C. RAMOs e E. REIS, 2001), poderemos aceitar um número certamente pouco superior a 500 mortos, atendendo a que uma semana após a tragédia ainda se retiravam alguns cadáveres das lamas acumuladas em Algés e se continuava a falar de vários desaparecidos que teriam sido arrastados até ao Tejo. Nestas situações, e em especial quando os poderes públicos não querem revelar toda a realidade, a imprecisão é grande - uns anos antes, em 1962, na bacia de Besós (Barcelona) ter-se-ão atingido "quase 800 mortos" e uns anos depois, em 1973, "quase 300" entre Granada, Almeria e Múrcia (J. OıcINACANTOS, 2006, p. 152). Também aí não existe um número preciso, faltando apenas saber se o motivo seria o mesmo do nosso país.

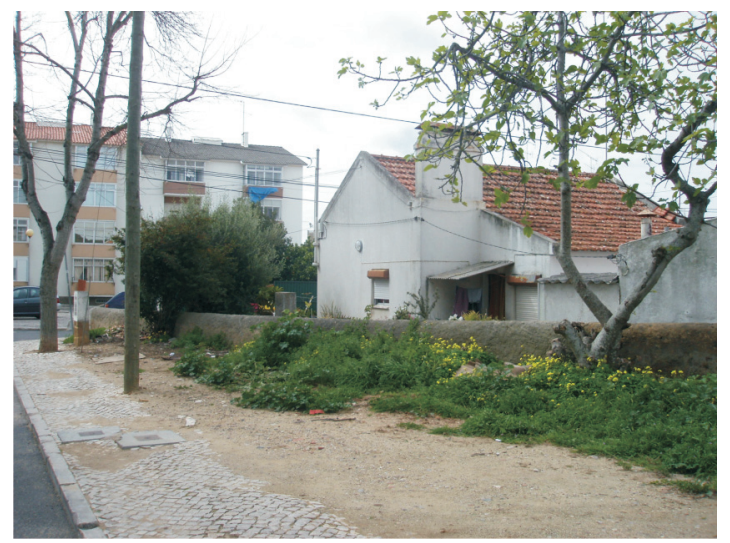

Fot. 3 - Alapraia, São João do Estoril. Casa térrea ainda existente e que às $23 \mathrm{~h} 30 \mathrm{~m}$ de 25 de Novembro de 1967 estava inundada. As ruas e o prédio em frente ainda não existiam.

2.4. As cheias rápidas na Região de Lisboa ocorridas em 1983 e 2008 têm sido comparadas com as de 1967. Há semelhanças, indubitavelmente.

Em 19 de Novembro de 1983, a precipitação registada durante $24 \mathrm{~h}$ na estação meteorológica de Lisboa (Gago Coutinho), foi de 126,6 mm. Tal como em 1967, os solos estavam já encharcados de água. No entanto, a manifestação do risco de cheias rápidas teve consequências muito menos gravosas em termos de vítimas humanas. A crise aconteceu. Foi grave. Apontam-se 7 mortos (D. B. FerReIRA, $1985 p$ 25), como também se apontam 10 (C. RAMOs e E. REIS, 2001 , p. 77). A diversidade dos números nada tem agora a ver com questões políticas - desde 1974, Portugal orgulhava-se de viver em democracia. Não 


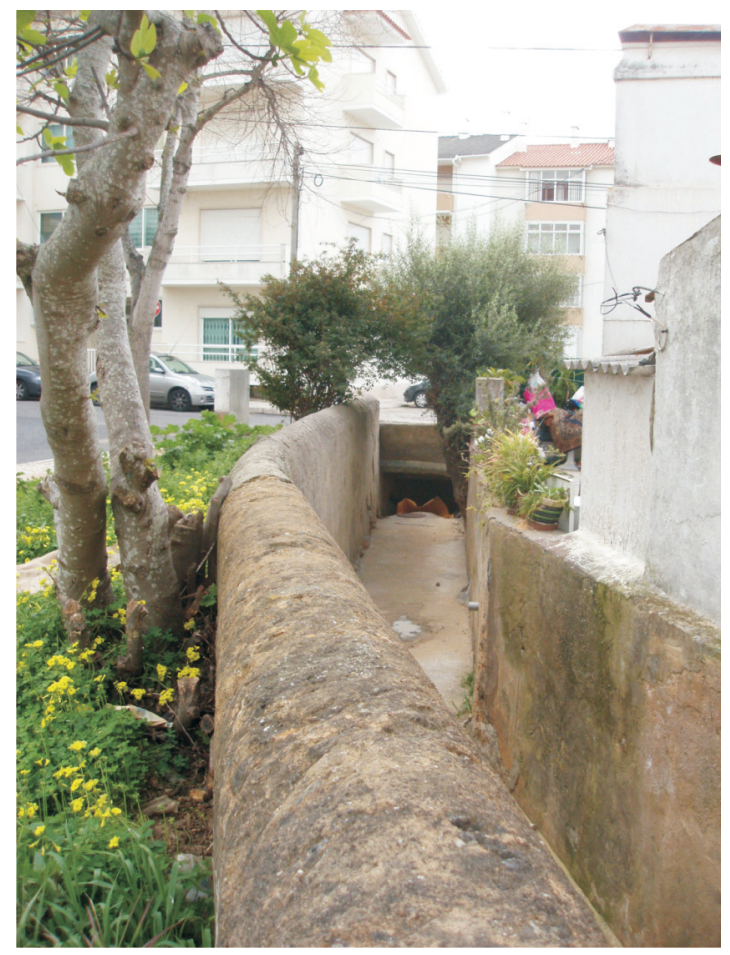

Fot. 4 - Alapraia, São João do Estoril. Encanamento da vala junto à casa da fotografia anterior. Ao fundo, brusca passagem a túnel por baixo da rua.

se sabe, portanto, quantas pessoas pereceram, mas não deverão ter ultrapassado a dezena; seguramente, não se tratou de um número que se possa comparar às centenas de mortos de 16 anos antes. A crise não teve a dimensão de uma catástrofe. Porquê? $A$ área atingida foi praticamente a mesma. Os processos foram os mesmos e a sua violência, particularmente na área de Cascais, foi grande. Mas as vulnerabilidades seriam ainda as mesmas? Claro que não. Muita legislação foi entretanto produzida e o poder local começara a ganhar força. Muitas obras se tinham feito. Muitas casas novas tinham sido construídas. À partida, o risco era bem inferior. Será de lembrar o referido caso de Nîmes, em 1988, onde também se perderam apenas 10 pessoas.

Em 18 de Fevereiro de 2008 verificaram-se, de novo, cheias rápidas na região de Lisboa. A precipitação registada em 24 h na estação de Lisboa (Gago Coutinho), foi de $129 \mathrm{~mm}$, ou seja, ligeiramente mais do que em 1983. No decurso da crise, com as ribeiras caudalosas destruindo muros e estradas, arrastando automóveis e até camionetas, houve quem estabelecesse a comparação com 1967. Três meses antes falara-se muito daquela catástrofe. Haviam passado 40 anos. Mas se a situação meteorológica apresentava semelhanças, as condições favoráveis à drenagem rápida eram bem diferentes - os solos encontravam-se quase secos, bem ao contrário de
1967, e, mais ainda do que em 1983, as vulnerabilidades tinham diminuído. A crise verificouse, mas o número de mortos foi apenas de 3 . Ficaram a dever-se a problemas de circulação rodoviária, típicos de uma ocorrência tão rápida que não deu tempo para a colocação no terreno dos habitualmente considerados agentes de protecção civil. A gestão eficaz de uma crise deste tipo é difícil, mas não é impossivel se houver uma preparação prévia de alguns elementos da população para, em casos destes, actuarem como agentes de protecção civil. Em teoria, aliás, cada cidadão é um agente de protecção civil.

\section{No futuro haverá cheias rápidas mais frequentes e mais violentas?}

3.1. Vai sendo habitual ouvir e ler-se que o clima está a sofrer alterações e que, por isso, no futuro, haverá muitas e piores cheias rápidas. Tem havido previsões catastróficas...Um "cientista" americano chegou mesmo a dizer que, dentro de 20 anos, Lisboa será atingida por furacões! A "previsão" teve honras de

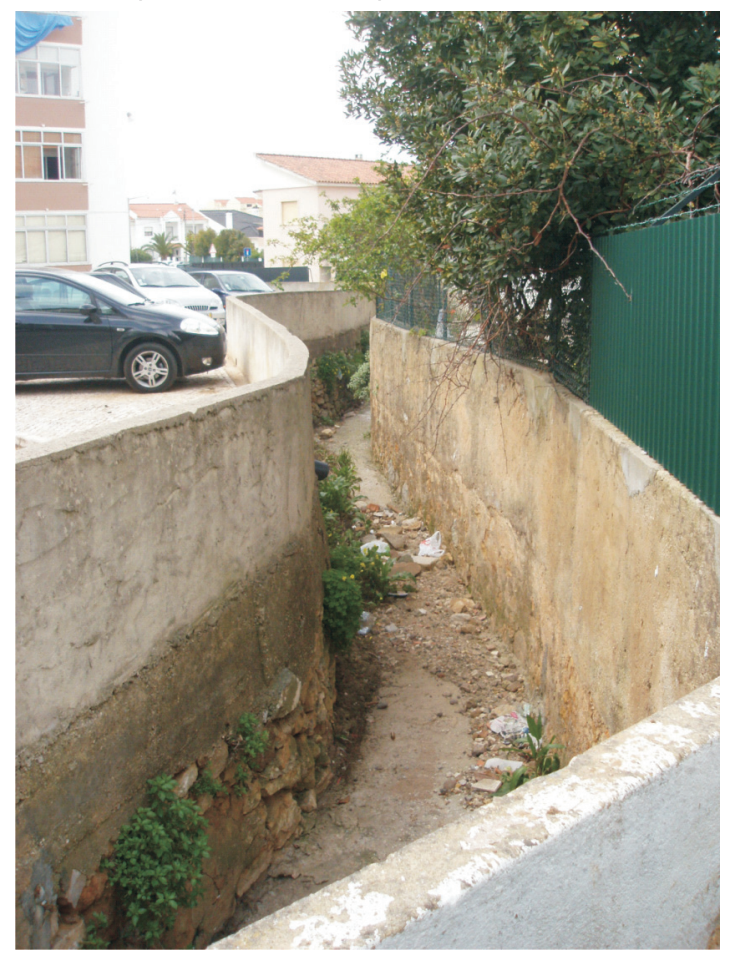

Fot. 5 - Alapraia, São João do Estoril. Encanamento da vala a jusante da rua da fotografia anterior. Claramente subdimensionado, o leito artificial mostra bem até onde, com mais frequência, chegam as águas - caso típico de agravamento de um hazard.

telejornal nacional. Já tinham desaparecido as notícias sobre o "buraco do ozono" e estavam já quase a desaparecer as notícias sobre o "aquecimento global". Começava-se a falar mais de "alterações 
climáticas" e aquela previsão catastrófica adaptavase perfeitamente à nova moda.

O aquecimento que desde há muito está provado cientificamente e que cada vez se conhece melhor é o das cidades. Na realidade, como explica a geógrafa francesa Yvette Veyret-Mekdjian, "os climatólogos estão de acordo para sublinhar que as actividades industriais, as combustões, modificaram os climas sobre espaços reduzidos, em particular nas grandes aglomerações que são afectadas pela ilha de calor (até $10^{\circ}$ nas metrópoles tropicais como São Paulo, México, Bombaim)"..."Os registos meteorológicos indicam um aumento das médias de temperaturas desde há alguns decénios, mas à escala mundial são demasiado pouco numerosos ou muitas vezes demasiado recentes para concluir a favor de mudanças globais de clima" (Y. VEYRET-MEKDJIAN, 2001). Anos antes, outro geógrafo francês tinha já sido bem claro sobre esta matéria, referindo-se "à tirania dos computadores que relega para segundo plano a observação da natureza" e perguntando-se, perante $\circ$ elevado número de incertezas que salientara ao longo de quase 20 páginas de um texto muito críitico, como é que "tantos sábios do mundo inteiro podiam predizer - e com tal segurança! - os amanhãs apocalípticos" (J. Demangeot, 1996, p. 304). Em 10 Encontros sobre Riscos Naturais realizados em Coimbra entre 1993 e 2003, com dezenas de geógrafos e geólogos, nacionais e estrangeiros, nunca se fizeram previsões catastrofistas (F. REBELO, 2005 b).

"Alterações climáticas" foi designação que, em Portugal, entrou na moda, mas que não resiste à crítica dos geógrafos que alguma vez se dedicaram à Climatologia. Para o geógrafo, que tem por objecto de estudo um espaço profundamente diferenciado, que é a superfície da Terra, há numerosos climas. E o geógrafo, porque também estuda Geomorfologia, sabe que à superfície da Terra muitas rochas se alteram. Mas os climas não se alteram. Porque os climas não são realidades fixas, como as rochas. Os climas são estados médios da atmosfera. Os climas variam no espaço, por isso, há muitos climas diferentes. Mas os climas também variam no tempo, por isso, no mesmo espaço, ao longo do dia, ao longo do mês, ao longo do ano, ao longo dos decénios, dos séculos, dos milénios, os estados de tempo vão variando. A variabilidade dos estados de tempo não autoriza que se fale em clima com dados de um ano, nem de dez ou vinte. A Organização Mundial de Meteorologia decidiu, desde há muito, que são necessários 30 anos de médias para se poder caracterizar um clima. E um clima não é uma rocha que se altere mais depressa ou mais devagar.
Pode, todavia, falar-se de Climate Change? Mudança climática? Claro que pode. Como escreveu o grande meteorologista suíço Stephan Bader, "clima foi sempre sinónimo de mudança" (S. BADER, 1998). No entanto, mudança não é um sinónimo de catástrofe, nem sequer de risco. Mudança não é, obrigatoriamente, para pior...

No futuro, serão as chuvas intensas ainda mais intensas do que o foram no passado? Vimos atrás como houve episódios de chuvas intensas no século XIX. E se estivessem a funcionar todas as estações meteorológicas que existem hoje, sabendo-se que estes episódios são muito localizados no espaço, não teria sido possível encontrar episódios ainda mais violentos? O geomorfólogo encontra, frequentemente, na base de vertentes ou mesmo a entulhar cursos de água, depósitos de materiais heterométricos que correspondem a momentos de violência semelhante ou até superior, ocorridos por várias vezes ao longo do Quaternário. Alguns são claramente históricos.

Nada nos autoriza a imaginar que as chuvas serão forçosamente mais intensas no futuro, embora tenhamos consciência de que uma vez ou outra possam ser. No domínio mediterrâneo, há bastantes exemplos de chuvas muito mais intensas do que as que na área de Lisboa foram responsáveis por parte das condições conducentes às cheias rápidas de 1967, 1983 e 2008. Há que ter consciência da importância da componente natural do risco.

\subsection{A grande diferença entre a região de Lisboa em} 1967 e a região de Lisboa no presente está no crescimento das áreas urbanas. A população aumentou. Há hoje mais superfície construída nos arredores da capital.

Poderá, então, falar-se de um aumento dos factores de agravamento das cheias? Em certos locais é visível que sim. A superfície construída, mais os espaços de estacionamento e de circulação que lhe correspondem, originam, por vezes, impermeabilizações exageradas. A dimensão das manilhas, estabelecida para escoamento de caudais médios, não é a conveniente para resolver problemas de ponta. $O$ encanamento de cursos de água nem sempre parece ter sido estudado para escoamentos de caudais de uma cheia rápida (Fot. 1 a 5). Mas ainda se está a tempo de evitar um acréscimo dos factores de agravamento. Não se esqueça o ensinamento das crises anteriores. Procure-se um bom dimensionamento dos canais de escoamento artificial. Evitem-se impermeabilizações exageradas nas novas urbanizações, utilizando pavimentos diferentes dos actuais asfaltos ou cimentos. Proceda-se à arborização e ao 
ajardinamento de espaços não construídos. Impõese, por um lado, atrasar a resposta do escoamento às chuvas intensas e, por outro lado, diminuir a velocidade do escoamento.

Haverá aumento das vulnerabilidades? Não obrigatoriamente! Cumpram-se as leis existentes para áreas de risco de inundação. Nos últimos anos, há legislação muito clara sobre construção em áreas inundáveis. Em certos casos, são exigidos mapas de risco de inundação. A elaboração deste tipo de mapas não é fácil, mas é fundamental - há que recordar as cheias anteriores, mas não esquecer todos os factores de agravamento que entretanto se desenvolveram a montante ou no próprio local em estudo e que as poderão tornar ainda mais rápidas ou mais extensas, fazendo com que espaços que antes não eram vulneráveis passem a ser.

No entanto, o que se afigura mais importante é evitar o regresso à pobreza de 1967, patente no elevado número de barracas de madeira isoladas ou juntas nos chamados "bairros de lata", muitas delas implantadas em áreas de risco, como talvegues e leitos de inundação. Os mais de 500 mortos da catástrofe de 1967 deveram-se principalmente a isso. Prédios bem construídos nas mesmas áreas apresentam risco bem menor em termos de eventuais perdas humanas, mas não deixam de o apresentar se tiverem pessoas a viver em caves e andares térreos; quanto aos bens existentes em garagens e estacionamentos o risco é elevado, mas a sua eventual perda não assumiria a dimensão de uma catástrofe, grau de crise que deverá ser especificamente utilizado para o caso de muitas perdas humanas.

Sobressai, portanto, de todas estas considerações a importância de um correcto ordenamento do território para a diminuição do risco relacionado com as chamadas flash floods.

\section{Conclusão}

Um novo olhar sobre os riscos é, deste modo, um olhar mais voltado para o Homem na sua cidade e na sua região, a curto prazo, do que para as previsões catastróficas que alguns fazem para o médio e o longo prazo. Stephan Bader tinha toda a razão não só em dizer que o "clima" foi sempre sinónimo de "mudança", mas também que "as sociedades complexas que se constituíram ao longo dos últimos 5000 anos nunca foram confrontadas até hoje com mudanças climáticas de uma amplidão comparável às que observamos em muitos exemplos de arquivos paleoclimáticos" (S. BADER, 1998).

Um novo olhar sobre os riscos é, então, um olhar que recuse ou, pelo menos, desdramatize previsões catastróficas, mas que analise as situações actuais no respeitante ao incremento da intensidade dos processos potencialmente perigosos e no respeitante às vulnerabilidades específicas para cada um desses processos.

Um novo olhar sobre os riscos é, acima de tudo, um olhar que conduza à consciencialização dos riscos e à sua prevenção no curto prazo através do cumprimento rigoroso da legislação existente, mas também da preparação devidamente hierarquizada dos agentes de protecção civil, tanto no sentido da percepção das situações de perigo, como da gestão de eventuais crises.

Nota - As fotografias inseridas no texto foram tiradas pelo Autor em Março de 2008.

\section{Referências bibliográficas}

Amaral, llídio do (1968) - "As inundações de 25/26 de Novembro de 1967 na região de Lisboa". Finisterra, 3 (5), p. 79-84.

DaupHiné, André (2001) - Risques et Catastrophes. Observer-Spatialiser-Comprendre-Gérer. Paris, Armand Colin, $288 \mathrm{p}$.

Demangeot, Jean (1996) - Les Millieux "Naturels" du Globe. Paris, Armand Colin, $337 \mathrm{p}$.

BADER, Stephan (1998) - "Changement climatique? Radioscopie du climat de la Suisse". Climat et Risques Naturels - La Suisse en mouvement. Zurich, ETH, p. 23-75.

FAugères, Lucien (1990 a) - "La dimension des faits et la théorie du risque". Le Risque et la Crise, Malta, Foundation for International Studies, p. 31-60.

Faugères, Lucien (1990 b) - "Géographie Physique ef Risques Naturels". Bull. Assoc. Géogr. Français, Paris, 2, p. 89-98.

Faugères, Lucien (1991) - "La Géo-cindynique, Géoscience du Risque". Bull. Assoc. Géogr. Français, Paris, 3, p. 179-193. 
Ferreira, Denise Brum (1985) - "Les dépressions convectives du Bassin Atlantique subtropical oriental". Finisterra, 20 (39), p. 25-45.

Martins, Alfredo Fernandes (1940) - O Esforço do Homem na Bacia do Mondego. Ensaio Geográfico. Coimbra, Edição de Autor, 299 p.

Ministère de l'Écologie et du Développement Durable (2004) - Crues du Gard 2002 : retour d'expérience. Paris, La Documentation Française, 325 p.

OlCina-Cantos, Jorge (2006) - Riesgos Naturales? I. Sequías e Inundaciones. Mataró, Editorial Da Vinci, Colección Geoambiente XXI, 220 p.

Péguy, Ch. P. (1970) - Précis de Climatologie. Paris, Masson et Cie., 468 p.

Ramos, Catarina e Rels, Eusébio (2001) - "As cheias do Sul de Portugal em diferentes tipos de bacias hidrográficas". Finisterra, 36 (71), p. 61-82.

Rebelo, Fernando (1997) - "Risco e crise nas inundações rápidas em espaço urbano. Alguns exemplos portugueses analisados a diferentes escalas": Territorium, 4, p. 29-47.

Rebelo, Fernando (2001) - Riscos Naturais e Acção Antrópica. Coimbra, Imprensa da Universidade, 274 p.

Rebelo, Fernando (2003) - Riscos Naturais e Acção Antrópica. Estudos e Reflexões. Coimbra, Imprensa da Universidade, 286 p. 2ª edição, revista e aumentada.

Rebelo, Fernando (2005 a) - "Riscos Naturais. Problemática da sua definição e adaptação aos principais elementos da teoria do risco". Análise e Gestão de Riscos, Segurança e Fiabilidade. C. Guedes Soares, A. P. Teixeira e P. Antão (Eds.). Lisboa, Edições Salamandra, vol. I, p. 301-315.

Rebelo, Fernando (2005 b) - Uma Experiência Europeia em Riscos Naturais. Coimbra, MinervaCoimbra, 123 p. +23 fotografias a preto e branco

Veyret-Mekdian, Yvette (2001) - Géographie des Risques Naturels. Paris, La Documentation Française, Documentation photographique, $63 p$.

Villain-GandossI, Christiane (1990) - "Origines du concept de risque en Occident. Les risques maritimes ou fortune de mer et leur compensations: les débuts de l'assurance maritime". Le risque et la crise, Malta, Foundation for International Studies, p. 71-84.

VilleVIeILle, Adelin (1997) - Les Risques Naturels en Méditerranée. Situation et Perspectives. Paris, Economica, Les Fascicules du Plan Bleu, 10, 160 p. 